\title{
TOWARDS A SYNERGY BETWEEN DANCE PEDAGOGY AND PRAXIS FOR NATIONAL DEVELOPMENT
}

\author{
Josephine Awele Odunze $1 ه$ (iD) Alex Asigbo $2 \square$ (iD) \\ Department of Theatre Arts Delta State University, Abraka, Nigeria \\ ${ }^{2}$ Department of Theatre and Film Studies Nnamdi Azikiwe University, Nigeria
}

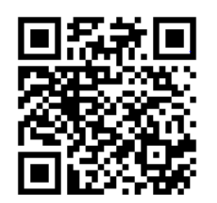

\section{ABSTRACT}

The initial objective of dance education was to development the art form and harness its potentials for societal development. That dance education in Nigeria's tertiary institutions of learning is largely seen as an isolated and purely academic exercise with little or no relevance to the real sector is hardly in contention as several studies attest to that reality. What is of concern is how to make it more relevant to the present milieu. Against universal trends, major developments in dance in Nigeria are driven by forces independent of academic influences. Various reasons have been advanced by scholars Ikideh (1987), Adeyemi (2010), Onyemuchara (2018) Onyemuchara, for instance, contends that the paucity of practice-based curriculum is the bane. Drawing from related disciplinary paradigms, this paper explores the possibility of synergizing the efforts of both the academic and professional/industry dance practitioners to make dance more relevant to national development.

Keywords: Dance, Pedagogy, Academic, Professional, National Development

Received 01 October 2021

Accepted 15 November 2021

Published 12 January 2022

\section{CorrespondingAuthor}

Josephine Awele Odunze, setusharma@outlook.com

\section{DOI}

10.29121/shodhkosh.v3.i1.2022.61

Funding: This research received no specific grant from any funding agency in the public, commercial, or not-for-profit sectors.

Copyright: (C) 2022 The Author(s). This is an open access article distributed under the terms of the Creative Commons Attribution License, which permits unrestricted use, distribution, and reproduction in any medium, provided the original author and source are credited.

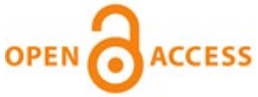

\section{INTRODUCTION}

Culture, of which dance is a subset, is an essential ingredient of social development: development in this context is concerned with conscious move away from primordial and archaic cultures to a more cohesive, dynamic, and secular ones. According to Nwodu (48) the human society is said to be culturally developed when such society creates conducive atmosphere for:

- cultural secularity i.e., where socio-political actions and activities are based on high level of rationality and empiricism

- high prevalence of universalistic norms i.e., human conducts and behaviors are guided by laws that are universal

- recognition of achievement over and above ascription i.e. individuals occupy positions of authority on the basis of merit rather than on the basis of family status and other demographic factors.

By underlining the transformative character of culture, its connection to development becomes obvious. Although development has many different notions, it intrinsically contains an element of progress or 'good change' (Chambers 1) - a (positive) transformation of the present situation. Development can also generally be associated with the reduction of poverty and the stimulation of economic growth. Various efforts, like the art form of dance, have the potential to achieve change for the better and reach those people who most need it. 
In many non-Western cultures dance plays a particularly important role in people's lives (Holzhausen 48). Salia Sanou (216) states that dance in Africa accompanies men and women, children, and old people through their lives every day. It is their medium to express joys and pains, their tool to link the spiritual to the physical world. Throughout human history, dance has been used as a tool for effective communication, playing various utilitarian roles in virtually all the major manifestations of human enterprises. Particularly, dance has also contributed significantly to the definition and re-shaping of the history of different cultures through time and space. Thus, as Adegbite (133) puts it, dance is easily regarded as a universal phenomenon, just like spoken word, or language and as one of the potent instruments/tools for communication and nation building; dance has been used as a symbol of unity ultimately aiding societal and behavioural changes.

Reinforcing the above position, Onyemuchara (150) adds that "dance is a symbolic art form that transcends the overall aesthetics of the body to the cultural essence of a people. It has continued to develop beyond being a cultural activity, to fulfilling other needs in the society, including economic, socio-political, educational, physical, psychological, and religious desires".

Against the backdrop of the utilitarian values of dance, Thomson (9) argues that it is imperative for society to push the boundaries of dance as an art and professional artists should be part of this process by facilitating this search for new forms of collaborative dance expression for development. It is for this reason that dance education was introduced into the tertiary education curriculum in Nigeria. To this end, there has been a growing establishment of theatre, dramatic and performing arts departments in more than seventy percent of Nigerian universities (Adeyemi, 152). One of the objectives for setting up these departments is to develop individual skills among students with the aim of training them to become professional artists, academics, media practitioners, etc. (Adeyemi, 152). Graduates of these institutions are therefore expected to work in academic institutions as well as professional theatres and troupes. It is however sad to note that despite the increasing number of academic institutions offering dance education in Nigeria, the contribution of dance education and academic dancers to socio-economic development at the formal and informal sectors is very minimal. Some clarification is required here; formal sector in the present context refers to all such government-promoted development-oriented programmes while the informal sector relates to similar private sector initiatives. To be clear also, the application of the term - professional - as against academic dance practitioners, refers contextually to industry practitioners of dance.

\section{STATEMENT OF THE PROBLEM}

That dance education in Nigerian tertiary institutions of learning is largely seen as an isolated and purely academic exercise with little or no relevance to the real sector is hardly in contention as several studies attest to that reality. In a society like Nigeria where the non-academically trained dancers and troupes are providing dance entertainment for more people, discourses on the significance of universitytrained dancers and formal dance pedagogy in general are often regarded as merely theoretical with nothing to contribute to the sustenance and enrichment of the cultural and socio-economic lives of the people.

What is of concern, therefore, is how to make formal dance pedagogy more relevant to the present milieu. Against universal trends, major developments in dance in Nigeria are driven by forces independent of academic influences. Most 
dance activities in the society, whether in traditional festivals, the home movies or the burgeoning music industry are performed not by university trained dancers but by individuals who learnt the art form informally. Notable leading dance exponents/practitioners and now trainers such as Kaffy, Mr. P of P Square fame, Dayo Adeladi, among others, took the centre stage of dance practice without any formal university training in dance. Today, they are the trainers of the bulk of dancers that are employed in the music industry. Kaffy, for instance, attended Yaba College of Technology for a while and went on to obtain a diploma in data processing from Olabisi Onabanjo University. She grew up with the aim of becoming an Aeronautic Engineer (Thisday, 12). She is currently the owner of Imagneto Dance Company, a dance instructor who has developed innovative visualisation-based methods for teaching dance and dance fitness in an accelerated-learning format (Pulse Nigeria, 5). In 2017, she created 'The Dance Workshop ' a dance convention aimed at training and mentoring professional dancers as well as promoting cultural exchange within the Nigerian dance industry. The 2017 Edition featured America's leading choreographer, AY Hollywood.

Mr. P of P Square fame studied Business Administration in the University of Abuja between 1999 and 2003. Today, he owns and promotes a continental dance project "Dance with Peter" that is sponsored by telecoms giant GLOBACOM and aired on satellite television to a global audience. In fact, majority of the members of the troupes from where the dancers used in music videos, home movies, cultural carnivals, etc., are privately or self-trained. In some cases, members of local dance troupes are hired on a one-off basis while in others, state cultural troupes are used. Okoyomoh (33) had noted that in most cultural troupes in Nigerian art councils, members are recruited in most cases irrespective of any formal qualification or training in the arts. Thus, the troupes are usually constituted mainly of non-formally or academically trained artists.

Formal dance pedagogy thus tends to remain indifferent to the cultureeconomic realities and needs of the society. Ikideh (19) argues that the problem is a function of premature inheritance of the literary culture without concomitantly integrating the oral tradition into the Nigerian educational curriculum, particularly at a point when most of the country's art and cultural expressions still reside in the oral tradition. Frank Whiting (58) had long contended that the mutual disdain which the academic and professional/practicing dancers hold against each other is responsible for the situation. He argued that the non-university-trained dancers who constitute the bulk of real sector practitioners, regard the academics as shirkers, who have chosen the ease and security of academic life because they never had the courage to face the uncertainties and furious competition of the public stage and people who profess to teach what can only be learnt in the hard school of experience and in front of paying audiences. On their parts, Onyemuchara (170) and Awuawaer (12) contend that the paucity of practice-based curriculum in the schools is the bane of academic dance in Nigeria. Irrespective of the divergence of views on what is responsible for the lack of synergy between academic and professional dance practice in Nigeria, the consensus is that something needs to be done to bridge the chasm. There is thus a marked knowledge gap on what needs to be done to make dance education more utilitarian in the country through a possible synergizing of both the academic and professional dance activities in the country. This paper explores possibilities for synergizing the efforts of both the academic and professional/practicing dance practitioners to make dance education in Nigeria's tertiary institutions more effective, responsive, and relevant to national development. 


\section{THE STATE OF ACADEMIC DANCE PRACTICE IN NIGERIA}

Robert W. Nicholls in Bakare (41) asserts that as life in modern society becomes increasingly technical, the need for increased participation in effective and aesthetic areas becomes apparent; therefore, dance as a functional socio-cultural root in the African cultural setup could play a part in a cross effective renaissance. However, as Nicholls submits in Onyemuchara (153), dance, especially in Nigeria, has been found wanting in this revival crusade - a situation that has hindered its capacity to address significant and/or salient issues through theme-based movements and gestures. This could be argued to be a function of the fact that dance appreciation in the modern Nigerian society has come to integrate wider parameters of measurement and evaluation, even by the partially illiterate audience due to increased exposure to western and other evolving dance forms and practices on the mass media.

The establishment of dance programmes in the tertiary institutions in Nigeria was to help harness the potentials of the dance art and enhance its utilitarian value to the country. However, as one of the earliest art forms, dance has continued to struggle for relevance and acceptance in the league of other performative genres such as drama and music (Onyemuchara 152). Akinsipe (77) argues that the problem is essentially due to the limited scope of the dance curriculum in Nigeria. According to him, while the related art forms of drama and music have for over half a century been accorded their distinct identities and autonomy as full departments in the tertiary institutions:

This is yet to be the case with dance as there is yet to be a single department of dance in the whole country. Dance is still studied under the theatre/dramatic/performing arts departments of our universities. Even then, none of these departments award any degree - not even a Bachelor of Arts degree in dance. This approach to the study of dance, no doubt, poses some problems to the proper study and development of the course in terms of scope, content and indeed, the end product. (Akinsipe 78).

Akinsipe states further that it is instructive to note that the study of drama started as part of English Language and in the English Department of many Nigerian universities with the University of Ibadan taking the lead, as far back as the 1960s. In all cases, after a while, drama became a full academic department, and this is the case with many theatre/dramatic/performing arts departments in Nigeria including Ahmadu Bello University whose drama unit stayed under the English department for close to thirty years. Even then, it existed all these years as a unit of the department awarding Bachelor of Arts (B.A. Hons.), Master of Arts (M.A.) and Doctorate (Ph. D) degrees. Similarly, as far back as 1960, a department of music was created in Nigeria at the University of Nigeria, Nsukka. Many other universities have followed suit and degrees up to Ph. D levels are being awarded in music. Hence, with the substantial evidence from both the movie and music industries, it is safe to contend that unlike dance, the study of music and drama as academic disciplines can today be said to be on course and responsive to society's development needs in Nigeria.

Against the backdrop of the capacity of dance to contribute to the economic and social needs of a nation Onyemuchara (152-153) states that the questions remain:

- Why has dance not advanced pedagogically especially in Nigerian institutions of higher learning?

- Of what importance is practice/practical to theory in dance teaching or training? 
- Why are there fewer student majors in dance than in other areas in the arts of the theatre such as directing, management, acting, media, costume, and make-up to name a few?

- Is dance pedagogy all about choreography and academic stage performance?

Admittedly, dance is performance but transcends mere performance. It derives especially from social culture. Its incorporation of movements and gestures, mime, drama, music, chants, acrobatics, among others, makes it interesting and attractive to humans universally. Understanding and teaching dance, therefore, afford one the opportunity to explore the art form in its widest sense. This includes an integration of efforts and resources of more people who could recreate from available themes and concepts - a synergy between the town and gown - which, hitherto, is lacking in Nigeria's institutions of higher learning due to the dearth of practice-oriented scholars. Unfortunately, this is largely lacking in the Nigerian system due to reasons already stated in this paper.

\section{WHAT NEEDS TO BE DONE?}

The example of the development of academic drama is instructive at this juncture. In conscious and determined bid to align with the developmental realities of society, academic dramatists synergized with their professional or practicing counterparts. In fact, upon realizing that they needed each other, both parties pulled their efforts and resources together. According to Illah (4), in the 1960s, the academic dramatists of the premier University of Ibadan realized that even where their productions focused on children, women and people generally, the productions were not available to these set of audiences in a language they could easily understand. This prompted the academic dramatist of the university to start thinking how to make drama more available and easily accessible to the people. Illah states further that in contrast to the reality of the sad situation of the academics, the non-academic theatres, and dramas of Hubert Ogunde and Duro Ladipo continued to thrive as they were available and accessible to the people. To this end, the School of Drama of the University of Ibadan began to work with several non-academic people. One such collaboration was with Kola Ogunmola in the production of Amos Tutuola's the Palmwine Drinkard (Adeyemi, 156).

Duro Ladipo was also known to have worked with both the School of Drama and the University's Institute of African Studies to stage Ladipo' s famous tragedy, Oba Koso (Adeyemi, 156). By engaging in these collaborations, the academic dramatists of the University of Ibadan succeeded in making their works and efforts relevant to social realities. Academic dance practitioners could take a cue from the experience of their drama counterparts in this regard. In other words, the dance curriculum could be re-designed to accommodate effective collaborations with industry practitioners as a determined step towards aligning academic dance with the development realities of society.

\section{CONCLUSION}

From the foregoing exposition, it is safe to state that apart from defining and teaching artistic creativity to dance students in universities, the exercise should be seriously structured and implemented by making it mandatory for dance students 
to serve internships with industry practitioners at various phases of the programme. This will expose them to the realities of the real sector so that when they conclude the programme they could seamlessly fuse into society as development agents.

Furthermore, collaboration between academic and industry dancers would most certainly eliminate that age-long mutual disdain which the academic and professional/practicing dancers hold against each other.

\section{REFRENCES}

Akinsipe, F. A. (2008). Dance Studies In The Nigerian University System : How Relevant to TfD ?. Mukabala, Journal of Performing Art and Culture, 1(1).

Justin, A. T. (2020). Interrogating Issues In Nigerian Dance Education. Journal of Dance Education. https://doi.org/10.1080/15290824.2020.1727907.

Bakare, O. R. (2007). Singing Old Tunes : Critical Comments on Welsh Asante's African Dance. Perspective in Nigerian Dance Studies. Ed. Chris Ugolo. Ibadan : Caltop Publications (Nigeria) Limited. 266-284.

Onyemuchara, C. E. (2018). Challenges of Teaching Practice-Based Dance Art In Nigeria : The Department of Theatre And Media Arts, FUOYE Model. Ekpoma Journal of Theatre and Media Arts. http://dx.doi.org/10.4314/ejotmas.v6i1-2.9.

Okoyomor, L. (2018). Managerial Challenges And Prospects of The Edo State Art Council. A Master's Dissertation of The University of Benin, Benin City. 